\title{
CYBER SECURITY AS AN EMERGENT INFRASTRUCTURE
}

\author{
Invited Talk
}

Dorothy E. Denning

Naval Postgraduate School, Monterey, California, USA

When I began studying computer security in late 1972 as a Ph.D. student at Purdue University, the field was in its infancy. There were few academics working in the area, no research conferences or journals devoted to the field, and no professional societies to join. Security papers were presented at conferences and published in journals that covered more established areas of computer science, such as operating systems, or that treated computing and telecommunications broadly. The number of publications and Ph.D. theses relating to computer security was small enough that it was possible to read the entire literature. If there was any security industry at all, I was not aware of it.

The field has changed dramatically in the 30 years that have passed. Now there is a multi-billion-dollar-a-year security industry offering thousands of products and services to everyone from large corporate enterprises to home computer users. There are more security conferences than I can keep track of, let alone attend, and enough publications to fill a library. Thirty-six universities have been declared Centers of Academic Excellence in Information Assurance Education, and numerous companies offer training in computer and network security and forensics. There are professional societies devoted to security, and certification programs for security technologies, operating environments, and security professionals. Information security has become a topic of conversation at board meetings and social gatherings. It is a priority in business and government. It has led to new laws and regulations, to new policies and procedures for handling information, and to a growing cadre of cyber cops and digital forensics specialists. It is on the agenda of Congress, the President, and international bodies. 
In short, cyber security has become an infrastructure in its own right. This infrastructure serves to protect computers and networks, and the information that is generated, acquired, processed, transmitted, and stored by them. Like many of the systems it protects, the security infrastructure is global and interconnected. It is growing and evolving, and will continue to do so as long as information technology itself evolves.

The talk explores this emergent infrastructure and the factors that are shaping its development. These factors are divided into five areas: threats, technology developments, economic factors, psychological factors, and social and political factors. These areas will be discussed after first describing the elements of the security infrastructure.

\section{SPEAKER}

Dorothy E. Denning is a professor in the Department of Defense Analysis at the Naval Postgraduate School. Her current work encompasses the areas of conflict and cyberspace, and information operations and iassurance. She has published 120 articles and four books, her most recent being Information Warfare and Security. She is an ACM Fellow and recipient of several awards, including the Augusta Ada Lovelace Award and the National Computer Systems Security Award. In November 2001, she was named a Time magazine innovator. Dr. Denning received the B.A. and M.A. degrees in mathematics from the University of Michigan and the Ph.D. degree in computer science from Purdue University. She has previously worked at Georgetown University, Digital Equipment Corporation, SRI International, and Purdue University. 